\title{
Whole Exome Sequencing in the Investigation of Growth Disorders, Including Patients with Primary IGF-1 Deficiency
}

\author{
Alexander A.L. Jorge \\ Unidade de Endocrinologia Genetica (LIM25), Hospital das Clinicas da Faculdade de Medicina, Universidade de \\ São Paulo (USP), São Paulo, Brazil
}

The conclusion of the genome project in 2003 resulted in a progressive increase in the demand for genetic tests in monogenic inherited diseases. This upward trend is motivated by a desire to establish a precise diagnosis and the etiology at the molecular level. Since 2007, the implementation of massively parallel sequencing technology, also known as next-generation sequencing (NGS), allowed the introduction of genomic analysis in clinical practice, mainly through whole exome sequencing (WES) studies [1]. WES consists of the simultaneous analysis of all protein-coding regions in the genome, which is known as exome. Human exome represents $1-2 \%$ of the human genome, containing approximately $30-50$ million base pairs distributed in $>180,000$ exons of 20,000 genes. The majority of recognizable disease-causing variants in monogenic diseases is located in the exon and intron boundary regions (splice junctions), both covered in WES. These characteristics of WES permitted the use of a single methodology by clinical laboratories to investigate several different genetic conditions, including rare diseases. Recent studies demonstrated the usefulness [2] and cost benefits of WES $[3,4]$ in the clinical investigation of patients with genetic conditions.

\section{KARGER}

() 2017 S. Karger AG, Basel

E-Mail karger@karger.com

www.karger.com/hrp
In the field of growth disorders, WES has been used to identify novel genes related to short stature $[5,6]$ or to expand the phenotype associated with previously recognized genes [7, 8]. Naturally, WES has been gradually introduced in clinical practice to investigate the genetic cause of short stature. In this scenario, the study published by Greta et al. [9] adds important information about the use of WES in the investigation of patients with severe primary insulin-like growth factor-1 (IGF-1) deficiency, also known as growth hormone insensitivity (GHI). They evaluated 22 patients from 17 families with short stature, low levels of IGF-1, but without GH deficiency. The WES analysis focused on the classical genes associated with GHI, such as GHR, STAT5B, IGFALS, and $I G F 1$, and a restricted list of 22 genes arbitrarily selected. In this cohort, the molecular etiology of the growth disorder was elucidated in 4 patients from 3 families. A homozygous loss of function variant in GHR was found in 2 siblings. Additionally, they identified 2 patients with pathogenic de novo variants in genes not classically associated with GHI: HRAS and FAM111A, previously described as causing Costello syndrome and Kenny-Caffey syndrome, respectively. None of these 2 patients had a 
phenotype that allowed the clinical diagnosis to trigger a candidate gene approach. A previous study that investigated severe short stature children of unknown cause through WES also identified patients with unexpected molecular defects, including atypical Noonan and Kenny-Caffey syndromes [10].

Those results highlight one of the advantages of using WES to investigate rare growth disorders: its ability to identify a clear pathogenic variant that establishes a diagnosis difficult to make based on clinical findings. In contrast, another finding in the present study exposed one of the main challenges when using WES: the significant number of variants whose importance is uncertain for the patients' phenotype, and which are for this reason classified as variants of unknown significance (VUS). It is de- sirable that all variants could be classified as pathogenic or benign. For this propose, it is necessary to (1) expand functional studies; (2) improve public databases of variants in healthy individuals, and (3) develop more accurate bioinformatics tools to reduce the number of variants classified as VUS and allow a better interpretation on a clinical basis of molecular results derived from WES. Nevertheless, the present study and previous ones reinforce the role of WES in the genetic investigation of children with short stature, including those with GHI.

\section{Disclosure Statement}

The author declares there is no conflict of interest that could be perceived as influencing the impartiality of the published text.

\section{References}

$>1$ de Bruin C, Dauber A: Insights from exome sequencing for endocrine disorders. Nat Rev Endocrinol 2015;11:455-464.

-2 Yang Y, Muzny DM, Xia F, et al: Molecular findings among patients referred for clinical whole-exome sequencing. JAMA 2014;312: 1870-1879.

-3 Tan TY, Dillon OJ, Stark Z, et al: Diagnostic impact and cost-effectiveness of wholeexome sequencing for ambulant children with suspected monogenic conditions. JAMA Pediatr 2017;171:855-862.

4 Stark Z, Schofield D, Alam K, Wilson W, Mupfeki N, Macciocca I, Shrestha R, White SM, Gaff C: Prospective comparison of the cost-effectiveness of clinical whole-exome sequencing with that of usual care overwhelmingly supports early use and reimbursement. Genet Med 2017;19:867-874.

$\checkmark 5$ Hisado-Oliva A, Ruzafa-Martin A, Sentchordi L, Funari MFA, Bezanilla-Lopez C, Alonso-
Bernaldez M, Barraza-Garcia J, RodriguezZabala M, Lerario AM, Benito-Sanz S, AzaCarmona M, Campos-Barros A, Jorge AAL, Heath KE: Mutations in C-natriuretic peptide (NPPC): a novel cause of autosomal dominant short stature. Genet Med 2017, DOI 10.1038/gim.2017.66.

-6 Dauber A, Munoz-Calvo MT, Barrios V, Domene HM, Kloverpris S, Serra-Juhe C, Desikan V, Pozo J, Muzumdar R, MartosMoreno GA, Hawkins F, Jasper HG, Conover CA, Frystyk J, Yakar S, Hwa V, Chowen JA, Oxvig C, Rosenfeld RG, Perez-Jurado LA, Argente J: Mutations in pregnancy-associated plasma protein A2 cause short stature due to low IGF-I availability. EMBO Mol Med 2016; 8:363-374.

7 de Bruin C, Finlayson C, Funari MF, Vasques GA, Lucheze Freire B, Lerario AM, Andrew M, Hwa V, Dauber A, Jorge AA: Two patients with severe short stature due to a FBN1 muta- tion (p.Ala1728Val) with a mild form of acromicric dysplasia. Horm Res Paediatr 2016;86: 342-348.

8 Nilsson O, Guo MH, Dunbar N, Popovic J, Flynn D, Jacobsen C, Lui JC, Hirschhorn JN, Baron J, Dauber A: Short stature, accelerated bone maturation, and early growth cessation due to heterozygous aggrecan mutations. J Clin Endocrinol Metab 2014;99:E1510-E1518.

$>9$ Grosse G, Hilger A, Ludwig M, Reutter H, Lorenzen F, Even G, Holterhus P-M, Woelfle J, German GHI Study Group: Targeted resequencing of putative growth-related genes using whole exome sequencing in patients with severe primary IGF-I deficiency. Horm Res Paediatr 2017, DOI: 10.1159/000480505.

$>10$ Guo MH, Shen Y, Walvoord EC, Miller TC, Moon JE, Hirschhorn JN, Dauber A: Whole exome sequencing to identify genetic causes of short stature. Horm Res Paediatr 2014;82: 44-52. 